\title{
Prevalence of diabetes and obesity in association with prematurity and growth restriction
}

This article was published in the following Dove Press journal:

Diabetes, Metabolic Syndrome and Obesity:Targets and Therapy 6 July 2017

Number of times this article has been viewed

\author{
Gretchen Kopec \\ Prem S Shekhawat \\ Maroun J Mhanna \\ Department of Pediatrics, \\ MetroHealth Medical Centre, \\ Case Western Reserve University, \\ Cleveland, OH, USA
}

Correspondence: Maroun J Mhanna Department of Pediatrics, MetroHealth Medical Center, 2500 MetroHealth Drive, Cleveland, OH 44109, USA

$\mathrm{Tel}+\mathrm{I} 2167781346$

Fax + I 2167784223

Emailmmhanna@metrohealth.org

\begin{abstract}
Intrauterine growth restriction (IUGR) is when fetuses and newborn infants have not reached their true growth potential as genetically defined. Fetuses with IUGR develop in a less than ideal environment that leads to epigenetic changes and marks infants' metabolism for the rest of their lives. Epigenetic changes affect insulin-like growth factor-1 (IGF-1) levels and lead to insulin resistance and ultimately to a metabolic syndrome. The metabolic syndrome is a constellation of illnesses that raise one's risk for type 2 diabetes mellitus, coronary artery disease, and ischemic heart disease, including hypertension, dyslipidemia, central obesity, insulin resistance, and inflammation. The association between IUGR or prematurity and longterm insulin resistance, obesity, hypertension, and metabolic syndrome remains unclear. While studies have shown an association, others have not supported such association. If alteration of intrauterine growth can ultimately lead to the development of metabolic derangements in childhood and adulthood, and if such association is true, then early interventions targeting the health of pregnant women will ensure the health of the population to follow.
\end{abstract}

Keywords: diabetes, obesity, low birth weight infants, metabolic syndrome

\section{Introduction}

As technology continues to improve, the survival of premature infants continues to improve as well. ${ }^{1}$ Also, the prevalence of obesity continues to increase among children and adolescents in the USA and across the world. ${ }^{2}$ Obesity in itself leads to lower highdensity lipoprotein (HDL) cholesterol, higher systolic and diastolic blood pressures, higher triglyceride, and higher hemoglobin A1c (HbA1c) levels. ${ }^{3}$ Prematurity has its own risk factors, and a long-term follow-up study shows a relationship between prematurity and early death from congenital anomalies, cardiovascular disease, respiratory illnesses, and endocrine disorders. ${ }^{4}$ Intrauterine growth impairment has its own risk factors. The "Barker Hypothesis" or the "Thrifty Hypothesis" supports the association between intrauterine growth and ultimate adult health. ${ }^{5}$ In an ill environment, a fetus adapts to survive. Such fetal adaptation can have long-term health consequences. The fetus can be exposed to poor nutrition such as in the case of placental insufficiency and maternal undernourishment, or the fetus can be exposed to overnutrition such as in the case of maternal obesity and gestational diabetes. ${ }^{6}$ Under- or overnutrition may lead to future changes via epigenetic modifications of DNA structures. These changes can lead to insulin resistance and ultimately to a higher rate of metabolic syndrome and obesity in adulthood. ${ }^{7}$ In this review, we discuss growth restriction and prematurity and their effects on insulin resistance, hypertension, obesity, and metabolic syndrome and the role of epigenetics. submit your manuscript f in $\square$ 


\section{Methods}

Multiple PubMed-indexed searches were performed using the following keywords in different combinations: intrauterine growth restriction (IUGR), small for gestational age (SGA), prematurity, hypertension, metabolic syndrome, insulin resistance, diabetes mellitus, epigenetics, and obesity. The articles were narrowed down based on relevance to the topic. Original studies were included. Additional references were incorporated after relevant references were taken from review articles.

In our review, IUGR was defined as an intrauterine growth restriction during the later trimesters. SGA was defined as infants with a birth weight below the 10th percentile for gestational age. A newborn can be IUGR, SGA, both, or neither. Newborns who are IUGR but not SGA may have originally developed in utero along a normal percentile in the first trimester but had growth restriction during later trimesters, remaining greater than the 10th percentile and thus IUGR but not SGA. One can also be constitutionally small, due to genetically small parents, but can have normal growth and cannot be considered IUGR. ${ }^{8}$ The classification of infants according to birth weight, gestational age, and growth restriction is essential for outcome studies. Low birth weight (LBW) infants $(<2,500 \mathrm{~g})$ have a 5-30 times higher mortality rate in the perinatal period compared to their appropriate for gestational age (AGA) counterparts. ${ }^{9}$ In a study by Campbell et al, ${ }^{10}$ infants with severe SGA (defined as birth weight $<3$ rd percentile) were associated with maternal smoking during pregnancy with an odds ratio (OR) of 5.3, preeclampsia (OR 4.6), threatened preterm labor (OR 3.9), and primiparity (OR 2.4). Infants with moderate SGA (birth weight 3 rd to 10th percentile) were associated with primiparity (OR 1.9) and prepregnancy underweight (OR 2.4). These results led the authors to the conclusion that the severe and moderate SGA infants represent two different cohorts of infants. Severe SGA infants consist mainly of IUGR infants, while moderate SGA infants are a heterogeneous group of IUGR infants and constitutionally small infants. ${ }^{10}$

\section{Epigenetics}

Cardiovascular risk factors, such as hypertension, dyslipidemia, and metabolic syndrome, were originally thought to be inheritable. However, recent developments have shown that DNA methylation and histone modification are the bases of epigenetic modification that leads to the alteration of the transcription of DNA without altering the DNA sequence itself. ${ }^{11}$

DNA methylation occurs when a methyl group is placed on a DNA dinucleotide containing $\mathrm{CpG},{ }^{11}$ of which $70 \%$ are in the methylated state. ${ }^{12}$ The unmethylated $\mathrm{CpG}$ dinucleotides exist in great amounts within promoter regions within $\mathrm{CpG}$ islands. If these promoter regions are unmethylated, the gene is expressed. If, however, the $\mathrm{CpG}$ dinucleotide becomes methylated on the cytosine residue to produce 5-methylcytidine via DNA methyltransferase, the promoter, and therefore, the gene is silenced and is not transcribed into mRNA. This methylation also recruits nearby proteins to continue to add silencing alterations to histones close to the gene to strengthen the silencing signal. ${ }^{13,14}$ Also, methylation is involved in genetic imprinting, such as Prader-Willi syndrome or Angelman syndrome, and X chromosome inactivation or lyonization. ${ }^{12}$

Histones are proteins that wrap around DNA and act as the backbone of chromatin-forming nucleosomes and help to control transcription. When DNA is wrapped in a histone, it is not accessible for transcription into mRNA and is effectively silenced. Histone modification occurs on the amino $(\mathrm{N})$ termini of the histone. ${ }^{12}$ There are many different types of modification that include methylation, acetylation, phosphorylation, sumoylation, ubiquitination, adenosine diphosphate (ADP)-ribosylation, and citrullination. ${ }^{11}$ These modulations act by changing the charge of the histone or by altering the ability to access the histone or by both. ${ }^{11,12}$ Various modulations contribute to "histone code" that determines the state of chromatin, of which 51 different positions exist. These different states or positions of chromatin determine whether or not a gene will be transcribed and translated, affecting ultimately the gene expression. ${ }^{11}$

Epigenetics is thought to play a part in "fetal programming". ${ }^{11}$ In utero, the fetus is exposed to the maternal environment including her nutritional status. If a mother is undernourished, her infant can develop IUGR ${ }^{15}$ and later becomes at risk for developing metabolic syndrome and related diseases. ${ }^{16,17}$ This is thought to be due to epigenetics, acquired changes in histone code and DNA methylation, which occur in utero, that lead to alterations of the growing child's nutrition and eventually the adult's body habitus. ${ }^{11}$ This has been shown historically in the offspring of pregnancies that occur during times of famine, such as the Dutch Famine of 1944, ${ }^{18}$ the Leningrad Siege of World War II, ${ }^{11}$ and the Great Chinese Famine in the early 1960s. ${ }^{19}$ Children born after these times of famine went on to have higher incidences of coronary artery disease (CAD), diabetes, hypertension, and dyslipidemia. ${ }^{11,18,19}$ This is known as the Barker Hypothesis or "Developmental Origins of Health and Disease (DOHAD)". The thought is that the body is programmed in utero to prepare for an adverse nutritional environment after birth. ${ }^{14,20}$ 
While this can be attributed to poor maternal nutrition during development, however, those infants were also under prenatal exposure to maternal stress due to the famine or war, which could have also led to epigenetic changes, making this cohort different from IUGR fetuses related to different maternal circumstances. ${ }^{21}$ For instance, in a mouse model, the delivery of IUGR litters by chronically obese mothers was thought to be secondary to epigenetic changes of the fetal liver and placenta. ${ }^{22}$

\section{Insulin-like growth factor-I (IGF-I) and epigenetics}

Recent studies have shown that IGF-1 is regulated by epigenetics in adults. ${ }^{23}$ Humans with severe IGF-1 deficiency have insulin resistance. ${ }^{24}$ There is a correlation between IGF-1 levels and insulin sensitivity. IGF-1 lowers the risk for CAD by counter-regulating the action of C-reactive protein (CRP), which is thought to activate coronary artery endothelial cells via an inflammatory cascade. There is a reverse relationship between IGF-1 levels and risk of ischemic heart disease. ${ }^{25}$

Epigenetics plays a role in IGF-1 expression. Two different peptides that are thought to play a role in "cell proliferation, migration, and survival" act at two different times in life, such as the fetal and neonatal periods. Epigenetics works on two different promoters that control the expression of these peptides. ${ }^{26}$ Fetuses and newborn infants of mothers with utero-placental insufficiency have low IGF levels, and IGF-1 dysregulation persists in childhood, which can lead to insulin resistance and CAD. ${ }^{11,25}$ Similar findings have been found in rat models. ${ }^{11}$

\section{IUGR and insulin secretion}

IUGR is an aberration of fetal growth and has many definitions, but basically, it can be defined as the inability to reach one's genetic growth potential in utero. ${ }^{27,28}$ IUGR can be symmetrical or asymmetrical, which is determined by comparing an infant's weight to length and head circumference. Symmetrical IUGR refers to a symmetrical growth restriction to length, weight, and head circumference, whereas asymmetrical or "head-sparing" IUGR refers to an asymmetrical growth restriction with a relative sparing of head and sometimes length growth comparing to weight. Symmetrical IUGR is associated with intrinsic, congenital, and other causes that occur early in gestation. ${ }^{8}$ Symmetrical IUGR can be caused by genetic syndromes (trisomy 21, 13, and 18), congenital infections (toxoplasma, other viruses, rubella, cytomegalovirus, Herpes simplex infections), dwarfisms, maternal drug use (prescription and illegal), as well as some inborn errors of metabolism (fatty acid oxidation disorders). Asymmetrical IUGR is usually associated with extrinsic causes and causes that occur late in gestation. Asymmetrical causes of IUGR are usually related to placental insufficiency, placental dysfunction, or lack of nutrients. ${ }^{29,30}$ In developing countries, the most common cause of asymmetrical IUGR remains caloric restriction or undernutrition. In developed countries, asymmetrical IUGR remains a problem in poverty stricken areas $^{15}$ and it is associated with the hypertension spectrum, ${ }^{31,32}$ maternal diabetes, and vascular-related disorders such as lupus and smoking. ${ }^{33}$

Type 2 diabetes develops once a patient acquires both insulin resistance and decreased insulin secretion, whether it is due to decreased beta-cell mass or poor pancreatic function. Severely IUGR infants born $<1.5 \mathrm{~kg}$ have decreased beta cell mass. ${ }^{34}$ While some have shown a positive correlation between pancreatic beta-cell mass and birth weight, which is thought to be due to a compensation for insulin resistance. ${ }^{34}$ Other studies have shown a negative correlation, which is thought to be due to beta-cell failure. ${ }^{35,36}$

Insulin secretion is decreased in IUGR infants, most likely due to poor insulin sensitivity and therefore low demand. Young men who were born IUGR have 30\% lower insulin secretion in relation to their insulin sensitivity, reflecting a decreased insulin deposition index. ${ }^{37}$ Adults who were born IUGR are unable to secrete the amount of insulin needed to compensate for insulin resistance and have lost their insulin plasticity. ${ }^{38}$

\section{Metabolic syndrome and insulin resistance}

There is a controversy regarding the best definition of the metabolic syndrome. However, there is an agreement that the metabolic syndrome is related to a cluster of diseases that raises one's risk of cardiovascular disease, including insulin resistance, central obesity, hypertension, dyslipidemia, and inflammation. In a recent study, the prevalence of the metabolic syndrome was found to be as high as $35 \%$ among US adults. ${ }^{2}$

All definitions agree on a component of insulin resistance whether there is type 2 diabetes or glucose intolerance. In response to a glucose load, insulin is secreted by the pancreas, which leads to an increase in glucose uptake by the muscles and a decrease in endogenous production of glucose by the liver. When there is insulin resistance, the appropriate cells cannot take up glucose, namely muscle cells. This hyperglycemia is theorized to lead to glycosylated end products that can result in atherosclerosis. ${ }^{39}$ Meanwhile, hepatic glucose production continues to be unchecked, worsening the 
hyperglycemia. Insulin acts on insulin receptors via different pathways including the mitogen-activated protein (MAP) kinase pathway, which initiates nitric oxide vasodilation. The MAP kinase pathway leads to the activation of many other pathways that result in mitosis and inflammation. Also, MAP kinase is responsible for smooth muscle cell growth and proliferation via extracellular-related kinases (ERK). With insulin resistance there is an alteration of these pathways. Hypertension and vascular dysfunction develop because of a decrease in nitric oxide and overstimulation of smooth muscle cell proliferation. ${ }^{40,41}$

\section{Association between insulin resistance and growth restriction}

Many studies have found an association between insulin resistance and IUGR and SGA infants. Leger et al found that young adults who were born SGA had higher glucose, insulin, and proinsulin concentrations than adults who were born AGA. Also, SGA adults were found to be shorter than their AGA counterparts by $4.5 \mathrm{~cm}$ for men and $3.94 \mathrm{~cm}$ for women (Table 1). ${ }^{42}$

In a study of 77 children, at the age of 10 years, and who were born preterm, SGA term, or AGA term, Kistner et al studied the impact of a compromised intrauterine or extrauterine environment on glucose homeostasis. In their study, the authors found that SGA infants had higher insulin levels and insulin resistance than their controls, suggesting peripheral insulin resistance. Also, the authors found that preterm infants had an attenuation in insulin-like growth factor-binding protein-1 (IGFBP-1) response during an oral glucose tolerance test (OGTT), suggesting a hepatic insulin resistance. ${ }^{33}$ Similarly, in a study of young adults born prematurely and SGA, Rotteveel et $\mathrm{al}^{43}$ found that preterm SGA adults have increased triglycerides and insulin during a mixed meal test.

\section{Association between insulin resistance and gestational age}

Many studies have found an association between insulin resistance and lower gestational age. Wang et al found an inverse relationship between gestational age and insulin levels at birth and during childhood. The authors found that early term infants had insulin levels that were 1.13-fold higher than insulin levels seen in term infants. Also, in comparison to term infants, they found a 1.45- and 2.05-fold higher insulin levels in late and early preterm infants, respectively. Similar trends in insulin levels were seen even during childhood. ${ }^{44}$ Similarly, in a study of 630,090 infants (including 27,953 premature babies), Crump et $\mathrm{al}^{45}$ found that adults with a history of prematurity were more likely to be prescribed insulin and oral medications for diabetes as adults (with an OR of 1.13) (Table 1).

In a study of 100 adults who were $<1,000 \mathrm{~g}$ at birth or extremely LBW (ELBW) infants, Morrison et $\mathrm{a}^{46}$ found that ELBW adults, at the age of 32 years, were four times more likely to develop dysglycemia (diabetes or prediabetes) and to have higher systolic and diastolic blood pressures than adults who were born a term. Similarly, in a study of 163 adults who were $<1,500 \mathrm{~g}$ at birth or very LBW (VLBW) infants, Hovi et $\mathrm{al}^{47}$ found that VLBW adults had higher insulin resistance, glucose intolerance, and higher blood pressures than adults who were born at term. Also in another study, Rotteveel et $\mathrm{al}^{48}$ found that young adults born prematurely have higher insulin resistance, whether AGA or SGA compared to fullterm controls.

\section{Metabolic syndrome and obesity}

A key concept behind metabolic syndrome is the overabundance of energy and the mishandling of the storage of that energy. Energy intake exceeds energy output. This is seen

Table I Association between growth restriction, prematurity, and insulin resistance

\begin{tabular}{|c|c|c|}
\hline Reference & Population & Major findings \\
\hline Leger et $\mathrm{al}^{42}$ & Young adults born SGA & SGA adults have higher glucose, insulin, and proinsulin and shorter than AGA adults \\
\hline \multirow[t]{2}{*}{ Kistner et $\mathrm{al}^{33}$} & 10-year old children born & SGA infants have higher peripheral insulin resistance \\
\hline & prematurely, SGA or AGA & Preterm infants have higher hepatic insulin resistance \\
\hline Rotteveel et al ${ }^{48}$ & Adults born preterm SGA & Increased triglycerides and insulin during a mixed meal test \\
\hline Wang et $\mathrm{al}^{44}$ & $\begin{array}{l}\text { Term and early preterm infants at } \\
\text { birth and in early childhood }\end{array}$ & $\begin{array}{l}\text { Inverse relationship between gestational age and insulin levels at birth and during } \\
\text { childhood }\end{array}$ \\
\hline Crump et $\mathrm{al}^{45}$ & Adults with a history of prematurity & $\begin{array}{l}\text { They are more likely to be prescribed insulin and oral medications for diabetes as } \\
\text { adults }\end{array}$ \\
\hline Morrison et $\mathrm{al}^{46}$ & Adults born ELBW infants & $\begin{array}{l}\text { Adults who were ELBW infants are four times more likely to develop diabetes/ } \\
\text { prediabetes than adults who were born at term }\end{array}$ \\
\hline Hovi et $\mathrm{al}^{47}$ & Adults born VLBW infants & $\begin{array}{l}\text { VLBW adults had higher insulin resistance and glucose intolerance than adults who } \\
\text { were born at term }\end{array}$ \\
\hline
\end{tabular}

Abbreviations: AGA, appropriate for gestational age; ELBW, extremely low birth weight; SGA, small for gestational age; VLBW, very low birth weight. 
in the central obesity component of the definition. Visceral adiposity remains key to the definition of metabolic syndrome and can be defined as an increased waist-to-hip ratio. Normally triglycerides are stored in adipocytes, but when energy intake exceeds the body's capacity, triglycerides can be stored in the liver, muscle cells, and visceral adipocytes (adipocytes surrounding vital organs), leading to central obesity. ${ }^{49}$ This storage of fat is inappropriate and contributes to the metabolic derangement of metabolic syndrome. It has been shown that individuals with metabolic syndrome possess excessively large peripheral adipocytes. And according to the Danforth theory, large adipocytes are unable to differentiate into smaller, new adipocytes. Therefore, there is a worsening ability to store excess energy and triglycerides, leading to the shifting of these molecules to visceral adipocytes, myocytes, and hepatocytes, worsening insulin resistance..$^{50,51}$

One of the roles of insulin is to inhibit lipolysis in fatty tissue. Therefore, the inability to inhibit free fatty acid release from the peripheral tissues is one of the first signs of insulin resistance and metabolic syndrome. ${ }^{50}$ Clinically, using serumfree fatty acids as a marker for metabolic syndrome is unreliable, since free fatty acid levels are inconsistent throughout the day. ${ }^{52}$ There is a constant stream of transport of fatty acids back and forth between the peripheral fatty tissue and the liver. If the balance is shifted toward accumulation in the liver, this can lead to hepatic steatosis or fatty liver disease. ${ }^{51,53}$

\section{Association between growth restriction and metabolic syndrome}

In a longitudinal, prospective cohort study of 1,308 individuals who were followed up to 22-30 years, Meas et al found that participants who were born SGA were more likely to suffer from insulin resistance and to have a greater rate of metabolic syndrome than their AGA controls. Also, the authors found that participants who were SGA had a twofold higher risk of developing MS during their 8-year follow-up period, and they attributed their findings to weight gain and fetal programming. ${ }^{54}$ However, in another study of 17,046 Belarusian children, Kramer et al found that SGA infants were shorter and thinner and had a lower body mass index (BMI) than their AGA contemporaries. While there is a discrepancy between the two studies, it must be taken in to account that there were significant differences in the studied populations. The socioeconomic conditions were quite different and most likely played a role in the final results (Table 2). ${ }^{55}$

\section{Association between prematurity and metabolic syndrome}

Using total body magnetic resonance imaging (MRI) studies of young adults (18-27 years old) who were born prematurely ( $\leq 33$ weeks gestational age) or at term, Thomas et al found that adults who were born prematurely had more total and abdominal adipose tissues and ectopic lipid contents than adults who were born at term. Also, they found higher hepatic and muscular intracellular lipid deposition in adults born prematurely. ${ }^{56}$ In a similar study of 376 adults who were born prematurely and 344 adults who were born at term, SipolaLeppanen et al found that adults who were born prematurely had a higher percentage of body fat and higher rates of metabolic syndrome (OR 3.7 for early preterm and 2.5 for late preterm). Also, they found that adults born prematurely had elevated blood pressures, larger waist circumferences, higher uric acid levels, and liver transaminase levels increasing their risk for cardiovascular disease. ${ }^{57}$ Using dual energy X-ray

Table 2 Association between growth restriction, prematurity, and obesity

\begin{tabular}{|c|c|c|}
\hline Reference & Population & Major findings \\
\hline Meas et $\mathrm{al}^{54}$ & 22-30-year old adults & $\begin{array}{l}\text { Adults born SGA were more likely to have insulin-resistance and metabolic syndrome than } \\
\text { adults born AGA }\end{array}$ \\
\hline Kramer et al ${ }^{55}$ & Children & Children born SGA were shorter and had a lower BMI than children born AGA \\
\hline Thomas et $\mathrm{al}^{56}$ & 18-27-year old adults & $\begin{array}{l}\text { Adults born prematurely ( } \leq 33 \text { weeks) had more total and abdominal adipose tissues and } \\
\text { ectopic lipid contents than adults born at term on total body MRI }\end{array}$ \\
\hline Sipola-Leppanen et $a^{57}$ & Adults & $\begin{array}{l}\text { Adults born prematurely had a higher percentage of body fat and higher rates of metabolic } \\
\text { syndrome }\end{array}$ \\
\hline Breukhoven et $\mathrm{al}^{58}$ & 18-24-year old adults & $\begin{array}{l}\text { Adults born prematurely had a higher percentage of total, trunk and limb fat mass than adults } \\
\text { born at term }\end{array}$ \\
\hline Sipola-Leppanen et $\mathrm{al}^{59}$ & $\begin{array}{l}\text { Adults born prematurely } \\
\text { and were VLBW }\end{array}$ & $\begin{array}{l}\text { Premature and VLBW adults had a lower REE, but higher REE/unit of lean body mass than } \\
\text { adults born at term }\end{array}$ \\
\hline Griffin and Cooke ${ }^{60}$ & 12-15-month old children & $\begin{array}{l}\text { Preterm infants had higher rates of adiposity at term-corrected gestational age, but they had } \\
\text { lower percent body fat mass at the age of } 12-15 \text { months when compared with infants born } \\
\text { at term }\end{array}$ \\
\hline
\end{tabular}

Abbreviations: AGA, appropriate for gestational age; BMI, body mass index; MRI, magnetic resonance imaging; REE, resting energy expenditure; SGA, small for gestational age; VLBW, very low birth weight. 
absorptiometry (DXA) on 455 young adults (18-24 years old), Breukhoven et al found that adults born prematurely had a higher percentage of total trunk and limb fat mass than adults born at term. However, it was interesting to find that adults born prematurely had a favorable lipid profile than adults born at term, protecting them against cardiovascular disease (Table 2). ${ }^{58}$

While most of the studies have shown an association between preterm birth and an increased risk of metabolic and cardiovascular diseases, other studies have not supported such association. In a study using indirect calorimetry and DXA, Sipola-Leppanen et al found that adults who were born prematurely with VLBW $(<1,500 \mathrm{~g}$ at birth) had overall a lower resting energy expenditure (REE) but a higher REE per unit of lean body mass than adults who were born at term. Their findings were supportive of the theory that such a higher metabolic rate could be protective against the development of obesity and other chronic diseases in adults born prematurely. ${ }^{59}$ In another study, Griffin and Cooke found that while preterm infants had higher rates of adiposity at term-corrected gestational age, they had lower percent body fat mass at the age of 12-15 months when compared with infants who were born at term. The authors showed that short-term rapid weight gain in preterm infants resulted in a similar body composition to term infants, arguing against the short-term risk of increased obesity in preterm infants. ${ }^{60}$

\section{Metabolic syndrome and hypertension}

Insulin is a vasodilator and increases sodium reabsorption by the kidneys. ${ }^{61}$ In patients with metabolic syndrome and insulin resistance, there is an alteration of the vasodilator effect $^{62}$ without the alteration of sodium reabsorption by the kidneys leading to hypertension. ${ }^{63}$ Also, insulin has sympathomimetic properties that are not altered with insulin resistance. Therefore, patients with insulin resistance can sometimes have decreased responses to antihypertensive medications, thought to be due to reduced vasodilation or increased sensitivity to salt. ${ }^{64-66}$ Hypertension and fatty acid metabolism interact via the renin-angiotensin-aldosterone system. Adipocytes produce angiotensinogen, and with an increase in adipocyte mass, there is an increase in the production of angiotensinogen, leading to hypertension. ${ }^{67}$ For instance, angiotensin-converting enzyme (ACE) inhibitors have been found to lower blood pressure and free fatty acid levels, which provide a potential therapy for the metabolic syndrome. ${ }^{67}$

\section{Association between growth restriction and hypertension}

Few studies have reported an association between growth restriction and later hypertension in childhood and adulthood. In a population-based study of 330,768 young men, Bergvall et $\mathrm{al}^{68}$ found that men who were born SGA had higher systolic blood pressures than men who were born with an appropriate weight for their gestational age regardless of their socioeconomic status or familial risk factor. In another study of 250,000 older adults who were born either prematurely ( $<35$ weeks) or small $(<2,100 \mathrm{~g}$ for boys and $<2,000 \mathrm{~g}$ for girls), Bonamy et al found an inverse relationship between birth weight and hypertension and that adults who were born SGA had $45 \%$ increased risk of hypertension, while they did not find any relationship between gestational age and hypertension. Their findings were supportive of the theory of poor fetal growth instead of prematurity being associated with hypertension later in life (Table 3) ${ }^{69}$

In a study of 232 men and women at the age of 50 years, of whom 108 were born IUGR and 124 were born AGA at term, Spence et al found that adults born IUGR had higher systolic and diastolic blood pressures than adults born AGA (systolic blood pressure [BP] 131.5 vs 127.1 and diastolic BP 82.3 vs 79.0, respectively). Also IUGR adults were more likely to be on antihypertensive medications than their controls. However, the difference was not statistically significant. ${ }^{70}$ Johansson et al, in a study of 329,495 men, found that blood pressures increased with decreasing birth weight for gestational age. Interestingly, the association between SGA and systolic high blood pressure was only found in men who were born late preterm ( $\geq 33$ weeks gestational age) and the risk for diastolic high blood pressure was only found significant in men who were born moderately preterm. ${ }^{71}$

\section{Association between prematurity and hypertension}

In a study of 204 ELBW infants $(<1,000 \mathrm{~g}$ at birth), who were followed up for 10 years, we have previously reported an increased prevalence of hypertension and obesity in our patients. And obesity was more prevalent among children who were hypertensive. ${ }^{72}$ In a study of 6,642 adolescents, Sipola-Leppanen et al found that adolescent girls who were born prematurely had higher systolic and diastolic blood pressures than their controls, but they did not have any differences in their serum lipid levels. However, adolescent boys born prematurely had a higher serum lipid levels than their controls, but they did not have any differences in blood pressures, supporting the theory of the association between 
Table 3 Association between growth restriction, prematurity, and hypertension

\begin{tabular}{|c|c|c|}
\hline Studies & Population & Major findings \\
\hline Bergvall et a $\left.\right|^{68}$ & Young men & $\begin{array}{l}\text { Men born SGA had higher systolic blood pressures than men born with an appropriate } \\
\text { weight for their gestational age }\end{array}$ \\
\hline Bonamy et a ${ }^{69}$ & Adults & $\begin{array}{l}\text { Inverse relationship between birth weight and hypertension. Adults who were born SGA } \\
\text { had } 45 \% \text { increased risk of hypertension. No relationship between gestational age and } \\
\text { hypertension }\end{array}$ \\
\hline Spence et $\mathrm{al}^{70}$ & 50-year old adults & Adults born IUGR had higher systolic and diastolic blood pressures than adults born AGA \\
\hline Johansson et $\mathrm{al}^{71}$ & Adult men & Blood pressures increased with decreasing birth weight for gestational age \\
\hline Mhanna et $\mathrm{al}^{72}$ & $\begin{array}{l}\text { 10-year old children who } \\
\text { were born ELBW infants }\end{array}$ & Increased prevalence of hypertension and obesity \\
\hline Sipola-Leppanen et $\mathrm{al}^{73}$ & Adolescents & $\begin{array}{l}\text { Adolescent girls born prematurely had higher systolic and diastolic blood pressures. } \\
\text { Adolescent boys born prematurely had a higher serum lipid levels }\end{array}$ \\
\hline Roberts et $\mathrm{a}^{74}$ & $\begin{array}{l}\text { 18-year old born at } \\
<28 \text { weeks gestation }\end{array}$ & $\begin{array}{l}\text { Higher systolic, diastolic, and mean arterial blood pressures in adolescents who were born } \\
\text { extremely premature }\end{array}$ \\
\hline $\begin{array}{l}\text { Siewert-Delle and } \\
\text { Ljungman }\end{array}$ & 49-year old men & $\begin{array}{l}\text { In adults born prematurely, there is an inverse relationship between gestational age and } \\
\text { systolic and diastolic blood pressures independent of birth weight }\end{array}$ \\
\hline Crump et $\mathrm{al}^{45}$ & $25-37-$ year old adults & Correlation between preterm birth and hypertension independently of fetal growth \\
\hline Keijzer-Veen et al $^{76}$ & $\begin{array}{l}\text { Young adults born at } \\
<32 \text { weeks and who were } \\
\text { VLBW }\end{array}$ & High prevalence of hypertension in adults who were born prematurely \\
\hline de Jong et $\mathrm{al}^{77}$ & Meta-analysis & Adults who were born prematurely or were VLBW have a higher systolic blood pressure \\
\hline
\end{tabular}

Abbreviations: AGA, appropriate for gestational age; ELBW, extremely low birth weight; IUGR, intrauterine growth restriction; SGA, small for gestational age; VLBW, very low birth weight.

prematurity and later development of cardiovascular risk factors. ${ }^{73}$ In a study of 18-year old adolescents who were born extremely premature ( $<28$ weeks), Roberts et al found higher systolic, diastolic, and mean arterial blood pressures in 136 adolescents who were born extremely premature in comparison to 120 controls. Of interest, blood pressures at the age of 8 years were associated with blood pressures obtained at the age of 18 years, emphasizing the importance of surveillance of children and adults who were born premature. ${ }^{74}$ In a follow-up study of an older population of 49-year-old men, Siewert-Delle and Ljungman found that, in adults who were born prematurely, there was an inverse relationship between gestational age and systolic $(R=-0.46 ; P=0.001)$ and diastolic ( $R=-0.44 ; P=0.01)$ blood pressures independent of birth weight. However, such relationship did not exist in adults who were born at term. Of interest, in adults who were born at term, there was a significant correlation between systolic $(R=0.34, P<0.001)$ and diastolic $(R=0.36 ; P<0.001)$ blood pressures and current BMI (Table 3 ). ${ }^{75}$

In a population-based study of adults who were 25-37 years old, Crump et al found a strong correlation between preterm birth and hypertension, using the number of prescription of antihypertensive medications as a mean to diagnose hypertension and its severity. The authors also found an inverse relationship between the number of prescriptions of antihypertensive medications and gestational age independently of fetal growth. The adjusted OR for using one or more antihypertensive medications increased with decreasing gestational age (from an OR of 1.25 in adults born near term to an OR of 2.51 in adults born extremely preterm) ${ }^{45}$ Similarly, in a prospective long-term follow-up study at the age of 19 years of young adults who were born at $<32$ weeks and who were VLBW, Keijzer-Veen et al found a high prevalence of hypertension in adults who were born prematurely in comparison to the general population. However, they did not find any association between IUGR, birth weight, gestational age, or plasma renin levels and blood pressures in early adulthood. ${ }^{76}$ In a meta-analysis of 27 observational studies, de Jong et $\mathrm{a}^{17}$ found that adults who were born prematurely or had a VLBW have a higher systolic blood pressure by a pool estimate of $2.5 \mathrm{mmHg}$ (95\% CI: $1.7-3.3 \mathrm{mmHg}$ ) than adults who were born at term. ${ }^{77}$

\section{Other aspects of metabolic syndrome}

Individuals with metabolic syndrome have a typical lipid profile of elevated triglycerides, low HDL, and uniquely, small, dense low-density lipoprotein (LDL). ${ }^{51,52}$ Insulin resistance and hyperglycemia lead to an elevated production and the release of fatty acids, both from the peripheral tissues and from the liver, and higher levels of glucose provide the carbon backbone for further triglyceride and lipid production. Insulin resistance increases peripheral lipolysis and also lipogenesis in the liver, leading to the elevated levels of free 
fatty acids. This leads to an increase in VLDL (triglyceride) production in the liver. Insulin resistance also leads to hypertriglyceridemia through a reduced breakdown of VLDL via decreased concentrations of lipoprotein lipase in peripheral tissues. ${ }^{52}$ Cholesterol ester transfer protein (CETP) alters both the composition of HDL and LDL in metabolic syndrome. CETP reduces the cholesterol ester content and increases the triglyceride content of HDL, resulting in smaller, denser HDL particles that are cleared faster from circulation. ${ }^{53} \mathrm{LDL}$ is similarly modified by CETP, resulting in analogous small, dense molecules. ${ }^{52}$ While HDL is cleared from circulation and therefore present in lower levels in the body, small, dense LDL is thought to be more atherogenic. This particular LDL is more atherogenic because of its decreased antioxidant properties, its ability to penetrate the arterial intima better, while also being more toxic to the endothelium, and its increased binding affinity to glycosaminoglycans. ${ }^{52,78}$

\section{Association between prematurity metabolic syndrome and cardiovascular risk factors}

Preterm birth has been associated with metabolic syndrome and cardiovascular risk factors. In a study of cardiovascular risk factors in preschool aged children who were born prematurely, Posod et al found that children born prematurely had higher cholesterol levels (OR 2.1), higher systolic and diastolic blood pressures, higher fasting glucose levels, and indicators of insulin resistance. The authors concluded that preterm infants have an unfavorable cardiovascular risk as early as preschool age. ${ }^{79}$ In a meta-analysis of 27 studies, Parkinson et al reviewed markers of metabolic syndrome in 17,030 adults who were born prematurely and were compared with 295,261 adults who were born at term. The authors found that premature birth was associated with higher systolic BP (4.2 $\mathrm{mm} \mathrm{Hg}$ ), diastolic BP (2.6 mm Hg), and LDL $(0.14 \mathrm{mmol} / \mathrm{L})$ in adulthood. Differences in BP were more pronounced in women than in men. However, they did not find any differences in glucose and insulin levels and intima-media thickness between adults born prematurely or at term. ${ }^{80}$ In the Helsinki Birth Cohort Study of risk factors associated with coronary heart disease and stroke, Kajantie et al reviewed 19,015 adults, of whom 1,143 were born prematurely, and found no differences in thrombotic or hemorrhagic strokes between adults born prematurely and their controls. However, they found that women who were born prematurely had a higher risk for coronary heart disease (hazard ratio of 1.98) ${ }^{81}$ In a population-based Swedish cohort study, Ueda et al reviewed the cerebrovascular and ischemic heart disease outcomes of 1,306,943 young adults, of whom 73,489 were born prematurely. The authors found that, while premature infants accounted for $5.6 \%$ of the cohort, they were responsible for $6.1 \%$ of all cases of cerebrovascular disease and $7.2 \%$ of all cases of ischemic heart disease. The finding was even more conspicuous when the effect of early prematurity was examined. Adults who were born before 32 weeks had a greater risk of cerebrovascular disease compared to the adults who were born at term (hazard ratio of 1.89). ${ }^{82}$ In a study of physical fitness in adults who were born prematurely, Tikanmaki et $\mathrm{al}^{83}$ found that adults who were born before 34 weeks and born 34-36 weeks had a lower muscular fitness than their controls. As preterm infants, adults born ELBW have similar cardiovascular profiles. Bassareo et $\mathrm{l}^{84}$ have shown that former ELBW adults have higher epicardial fat thickness, which is thought to be a cardiometabolic risk factor.

\section{Association between growth restriction metabolic syndrome and cardiovascular risk factors}

In a meta-analysis, Malin et al, while showing a small relationship, failed to show a significant relationship between birth weight $<10$ th percentile and adult morbidities, such as hypertension, cardiovascular disease, and diabetes. This is thought to be due to inconsistencies in definitions of LBW and IUGR and highlights the need for further studies to elucidate any association. ${ }^{85}$

\section{Conclusion}

Infants who are born prematurely or have growth restriction are exposed to unfavorable nutritional environments that lead to epigenetic changes. These changes can ultimately result in the development of insulin resistance, obesity, and dyslipidemia, the main components of the metabolic syndrome. While most studies have supported some associations between IUGR, prematurity or LBW, and progression toward insulin resistance, diabetes, dyslipidemia, metabolic syndrome, high blood pressure, and increased risk for cardiovascular diseases, other studies have not supported such associations. Further studies are needed to elucidate such associations and explore the possibilities of future therapies to protect the health of future generations starting at conception and during pregnancy.

\section{Disclosure}

The authors report no conflicts of interest in this work. 


\section{References}

1. Stoll BJ, Hansen NI, Bell EF, et al. Neonatal outcomes of extremely preterm infants from the NICHD Neonatal Research Network. Pediatrics. 2010;126(3):443-456.

2. Aguilar M, Bhuket T, Torres S, Liu B, Wong RJ. Prevalence of the metabolic syndrome in the United States, 2003-2012. JAMA. 2015;313(19):1973-1974.

3. Skinner AC, Perrin EM, Moss LA, Skelton JA. Cardiometabolic risks and severity of obesity in children and young adults. $N$ Engl J Med. 2015;373(14):1307-1317.

4. Crump C, Sundquist K, Sundquist J, Winkleby MA. Gestational age at birth and mortality in young adulthood. JAMA. 2011;306(11):1233-1240.

5. Vaag AA, Grunnet LG, Arora GP, Brons C. The thrifty phenotype hypothesis revisited. Diabetologia. 2012;55(8):2085-2088.

6. Gillman MW. Developmental origins of health and disease. $N$ Engl $J$ Med. 2005;353(17):1848-1850.

7. Gluckman PD, Hanson MA, Buklijas T, Low FM, Beedle AS. Epigenetic mechanisms that underpin metabolic and cardiovascular diseases. Nat Rev Endocrinol. 2009;5(7):401-408.

8. Thureen PJ, Anderson MS, Hay WW. The small-for-gestational age infant. NeoReviews. 2001;2(6):e139-e149.

9. Peleg D, Kennedy CM, Hunter SK. Intrauterine growth restriction: identification and management. Am Fam Physician. 1998;58(2):453-460, 466-467.

10. Campbell MK, Cartier S, Xie B, Kouniakis G, Huang W, Han V. Determinants of small for gestational age birth at term. Paediatr Perinat Epidemiol. 2012;26(6):525-533.

11. Lane RH. Fetal programming, epigenetics, and adult onset disease. Clin Perinatol. 2014;41(4):815-831.

12. Promega. Epigenetics; Protocols \& applications guide; 2013. Available from: https://www.promega.com/-/media/files/resources/paguide/a4/ chap16a4.pdf?la=en. Accessed June 26, 2017.

13. El Hajj N, Schneider E, Lehnen H, Haaf T. Epigenetics and life-long consequences of an adverse nutritional and diabetic intrauterine environment. Reproduction. 2014;148(6):R111-R120.

14. Simmons RA. Developmental origins of beta-cell failure in type 2 diabetes: the role of epigenetic mechanisms. Pediatr Res. 2007;61(5 pt 2):64R-67R.

15. Carlson SJ, Andrews MS, Bickel GW. Measuring food insecurity and hunger in the United States: development of a national benchmark measure and prevalence estimates. J Nutr. 1999;129(2S suppl):510S-516S.

16. Kerkhof GF, Willemsen RH, Leunissen RW, Breukhoven PE, HokkenKoelega AC. Health profile of young adults born preterm: negative effects of rapid weight gain in early life. J Clin Endocrinol Metab. 2012;97(12):4498-4506.

17. Casey PH, Bradley RH, Whiteside-Mansell L, Barrett K, Gossett JM, Simpson PM. Evolution of obesity in a low birth weight cohort. $J$ Perinatol. 2012;32(2):91-96.

18. de Rooij SR, Painter RC, Phillips DI, et al. Hypothalamic-pituitaryadrenal axis activity in adults who were prenatally exposed to the Dutch famine. Eur J Endocrinol. 2006;155(1):153-160.

19. Wang Y, Wang X, Kong Y, Zhang JH, Zeng Q. The Great Chinese Famine leads to shorter and overweight females in Chongqing Chinese population after 50 years. Obesity (Silver Spring). 2010;18(3):588-592.

20. Simmons RA. Developmental origins of diabetes: the role of oxidative stress. Best Pract Res Clin Endocrinol Metab. 2012;26(5):701-708.

21. van Deutekom AW, Chinapaw MJ, Jansma EP, Vrijkotte TG, Gemke RJ. The association of birth weight and infant growth with energy balancerelated behavior - a systematic review and best-evidence synthesis of human studies. PLoS One. 2017;12(1):e0168186.

22. Panchenko PE, Voisin S, Jouin M, et al. Expression of epigenetic machinery genes is sensitive to maternal obesity and weight loss in relation to fetal growth in mice. Clin Epigenetics. 2016;8:22.

23. Isaksson OG, Jansson JO, Sjogren K, Ohlsson C. Metabolic functions of liver-derived (endocrine) insulin-like growth factor I. Horm Res. 2001;55(suppl 2):18-21.
24. Guler HP, Zapf J, Froesch ER. Short-term metabolic effects of recombinant human insulin-like growth factor I in healthy adults. $N$ Engl $J$ Med. 1987;317(3):137-140.

25. Liu SJ, Zhong Y, You XY, Liu WH, Li AQ, Liu SM. Insulin-like growth factor 1 opposes the effects of C-reactive protein on endothelial cell activation. Mol Cell Biochem. 2014;385(1-2):199-205.

26. Brisson BK, Barton ER. Insulin-like growth factor-I E-peptide activity is dependent on the IGF-I receptor. PLoS One. 2012;7(9):e45588.

27. Maulik D. Fetal growth compromise: definitions, standards, and classification. Clin Obstet Gynecol. 2006;49(2):214-218.

28. Mayer C, Joseph KS. Fetal growth: a review of terms, concepts and issues relevant to obstetrics. Ultrasound Obstet Gynecol. 2013;41(2):136-145.

29. Cox P, Marton T. Pathological assessment of intrauterine growth restriction. Best Pract Res Clin Obstet Gynaecol. 2009;23(6):751-764.

30. Fu Q, McKnight RA, Callaway CW, Yu X, Lane RH, Majnik AV. Intrauterine growth restriction disrupts developmental epigenetics around distal growth hormone response elements on the rat hepatic IGF-1 gene. FASEB J. 2015;29(4):1176-1184.

31. Ounsted M, Moar VA, Scott A. Risk factors associated with small-for-dates and large-for-dates infants. Br J Obstet Gynaecol. 1985;92(3):226-232.

32. Odegard RA, Vatten LJ, Nilsen ST, Salvesen KA, Austgulen R. Preeclampsia and fetal growth. Obstet Gynecol. 2000;96(6):950-955.

33. Kistner A, Rakow A, Legnevall L, et al. Differences in insulin resistance markers between children born small for gestational age or born preterm appropriate for gestational age. Acta Paediatr. 2012;101(12): 1217-1224.

34. Van Assche FA, De Prins F, Aerts L, Verjans M. The endocrine pancreas in small-for-dates infants. Br J Obstet Gynaecol. 1977;84(10): 751-753.

35. Newsome CA, Shiell AW, Fall CH, Phillips DI, Shier R, Law CM. Is birth weight related to later glucose and insulin metabolism? - A systematic review. Diabet Med. 2003;20(5):339-348.

36. Mericq V, Ong KK, Bazaes R, et al. Longitudinal changes in insulin sensitivity and secretion from birth to age three years in small- and appropriatefor-gestational-age children. Diabetologia. 2005;48(12):2609-2614.

37. Jensen CB, Storgaard H, Dela F, Holst JJ, Madsbad S, Vaag AA. Early differential defects of insulin secretion and action in 19-yearold Caucasian men who had low birth weight. Diabetes. 2002;51(4): $1271-1280$

38. Gatford KL, Simmons RA. Prenatal programming of insulin secretion in intrauterine growth restriction. Clin Obstet Gynecol. 2013;56(3):520-528.

39. Intensive blood-glucose control with sulphonylureas or insulin compared with conventional treatment and risk of complications in patients with type 2 diabetes (UKPDS 33). UK Prospective Diabetes Study (UKPDS) Group. Lancet. 1998;352(9131):837-853.

40. Le Roith D, Zick Y. Recent advances in our understanding of insulin action and insulin resistance. Diabetes Care. 2001;24(3):588-597.

41. Cusi K, Maezono K, Osman A, et al. Insulin resistance differentially affects the PI 3-kinase- and MAP kinase-mediated signaling in human muscle. J Clin Invest. 2000;105(3):311-320.

42. Leger J, Levy-Marchal C, Bloch J, et al. Reduced final height and indications for insulin resistance in 20 year olds born small for gestational age: regional cohort study. BMJ. 1997;315(7104):341-347.

43. Rotteveel J, van Weissenbruch MM, Twisk JW, Delemarre-Van de Waal HA. Abnormal lipid profile and hyperinsulinaemia after a mixed meal: additional cardiovascular risk factors in young adults born preterm. Diabetologia. 2008;51(7):1269-1275.

44. Wang G, Divall S, Radovick S, et al. Preterm birth and random plasma insulin levels at birth and in early childhood. JAMA. 2014;311(6): 587-596.

45. Crump C, Winkleby MA, Sundquist K, Sundquist J. Risk of hypertension among young adults who were born preterm: a Swedish national study of 636,000 births. Am J Epidemiol. 2011;173(7):797-803.

46. Morrison KM, Ramsingh L, Gunn E, et al. Cardiometabolic health in adults born premature with extremely low birth weight. Pediatrics. 2016;138(4):e20160515. 
47. Hovi P, Andersson S, Eriksson JG, et al. Glucose regulation in young adults with very low birth weight. $N$ Engl J Med. 2007;356(20): 2053-2063.

48. Rotteveel J, van Weissenbruch MM, Twisk JW, Delemarre-Van de Waal HA. Infant and childhood growth patterns, insulin sensitivity, and blood pressure in prematurely born young adults. Pediatrics. 2008;122(2): 313-321.

49. Kelley DE, Mandarino LJ. Fuel selection in human skeletal muscle in insulin resistance: a reexamination. Diabetes. 2000;49(5):677-683.

50. Danforth E Jr. Failure of adipocyte differentiation causes type II diabetes mellitus? Nat Genet. 2000;26(1):13.

51. Eckel RH, Grundy SM, Zimmet PZ. The metabolic syndrome. Lancet. 2005;365(9468):1415-1428.

52. Miranda PJ, DeFronzo RA, Califf RM, Guyton JR. Metabolic syndrome: definition, pathophysiology, and mechanisms. Am Heart J. 2005;149(1):33-45.

53. Murakami T, Michelagnoli S, Longhi R, et al. Triglycerides are major determinants of cholesterol esterification/transfer and HDL remodeling in human plasma. Arterioscler Thromb Vasc Biol. 1995;15(11): 1819-1828.

54. Meas T, Deghmoun S, Alberti C, et al. Independent effects of weight gain and fetal programming on metabolic complications in adults born small for gestational age. Diabetologia. 2010;53(5):907-913.

55. Kramer MS, Martin RM, Bogdanovich N, Vilchuk K, Dahhou M, Oken E. Is restricted fetal growth associated with later adiposity? Observational analysis of a randomized trial. Am J Clin Nutr. 2014;100(1): 176-181.

56. Thomas EL, Parkinson JR, Hyde MJ, et al. Aberrant adiposity and ectopic lipid deposition characterize the adult phenotype of the preterm infant. Pediatr Res. 2011;70(5):507-512.

57. Sipola-Leppanen M, Vaarasmaki M, Tikanmaki M, et al. Cardiometabolic risk factors in young adults who were born preterm. Am J Epidemiol. 2015;181(11):861-873.

58. Breukhoven PE, Kerkhof GF, Willemsen RH, Hokken-Koelega AC. Fat mass and lipid profile in young adults born preterm. J Clin Endocrinol Metab. 2012;97(4):1294-1302.

59. Sipola-Leppanen M, Hovi P, Andersson S, et al. Resting energy expenditure in young adults born preterm - the Helsinki study of very low birth weight adults. PLoS One. 2011;6(3):e17700.

60. Griffin IJ, Cooke RJ. Development of whole body adiposity in preterm infants. Early Hum Dev. 2012;88(suppl 1):S19-S24.

61. Steinberg HO, Brechtel G, Johnson A, Fineberg N, Baron AD. Insulinmediated skeletal muscle vasodilation is nitric oxide dependent. A novel action of insulin to increase nitric oxide release. J Clin Invest. 1994;94(3): 1172-1179.

62. Tooke JE, Hannemann MM. Adverse endothelial function and the insulin resistance syndrome. J Intern Med. 2000;247(4):425-431.

63. Kuroda S, Uzu T, Fujii T, et al. Role of insulin resistance in the genesis of sodium sensitivity in essential hypertension. JHum Hypertens. 1999;13(4): 257-262.

64. Higashi Y, Sasaki S, Nakagawa K, Matsuura H, Chayama K, Oshima T. Effect of obesity on endothelium-dependent, nitric oxide-mediated vasodilation in normotensive individuals and patients with essential hypertension. Am J Hypertens. 2001;14(10):1038-1045.

65. ter Maaten JC, Voordouw JJ, Bakker SJ, Donker AJ, Gans RO. Salt sensitivity correlates positively with insulin sensitivity in healthy volunteers. Eur J Clin Invest. 1999;29(3):189-195.

66. Semplicini A, Ceolotto G, Massimino M, et al. Interactions between insulin and sodium homeostasis in essential hypertension. Am J Med Sci. 1994;307(suppl 1):S43-S46.
67. Egan BM, Greene EL, Goodfriend TL. Insulin resistance and cardiovascular disease. Am J Hypertens. 2001;14(6 pt 2):116S-125S.

68. Bergvall N, Iliadou A, Tuvemo T, Cnattingius S. Birth characteristics and risk of high systolic blood pressure in early adulthood: socioeconomic factors and familial effects. Epidemiology. 2005;16(5):635-640.

69. Bonamy AK, Norman M, Kaijser M. Being born too small, too early, or both: does it matter for risk of hypertension in the elderly? Am J Hypertens. 2008;21(10):1107-1110.

70. Spence D, Stewart MC, Alderdice FA, Patterson CC, Halliday HL. Intrauterine growth restriction and increased risk of hypertension in adult life: a follow-up study of 50-year-olds. Public Health. 2012;126(7):561-565.

71. Johansson S, Iliadou A, Bergvall N, Tuvemo T, Norman M, Cnattingius $\mathrm{S}$. Risk of high blood pressure among young men increases with the degree of immaturity at birth. Circulation. 2005;112(22):3430-3436.

72. Mhanna MJ, Iqbal AM, Kaelber DC. Weight gain and hypertension at three years of age and older in extremely low birth weight infants. J Neonatal Perinatal Med. 2015;8(4):363-369.

73. Sipola-Leppanen M, Vaarasmaki M, Tikanmaki M, et al. Cardiovascular risk factors in adolescents born preterm. Pediatrics. 2014;134(4): e1072-e1081.

74. Roberts G, Lee KJ, Cheong JL, Doyle LW; Victorian Infant Collaborative Study Group. Higher ambulatory blood pressure at 18 years in adolescents born less than 28 weeks' gestation in the 1990 s compared with term controls. J Hypertens. 2014;32(3):620-626.

75. Siewert-Delle A, Ljungman S. The impact of birth weight and gestational age on blood pressure in adult life: a population-based study of 49-year-old men. Am J Hypertens. 1998;11(8 pt 1):946-953.

76. Keijzer-Veen MG, Finken MJ, Nauta J, et al. Is blood pressure increased 19 years after intrauterine growth restriction and preterm birth? A prospective follow-up study in The Netherlands. Pediatrics. 2005;116(3):725-731.

77. de Jong F, Monuteaux MC, van Elburg RM, Gillman MW, Belfort MB. Systematic review and meta-analysis of preterm birth and later systolic blood pressure. Hypertension. 2012;59(2):226-234.

78. Packard CJ. LDL subfractions and atherogenicity: an hypothesis from the University of Glasgow. Curr Med Res Opin. 1996;13(7): 379-390.

79. Posod A, Odri Komazec I, Kager K, et al. Former very preterm infants show an unfavorable cardiovascular risk profile at a preschool age. PLOS One. 2016;11(12):e0168162.

80. Parkinson JR, Hyde MJ, Gale C, Santhakumaran S, Modi N. Preterm birth and the metabolic syndrome in adult life: a systematic review and meta-analysis. Pediatrics. 2013;131(4):e1240-e1263.

81. Kajantie E, Osmond C, Eriksson JG. Coronary heart disease and stroke in adults born preterm - the Helsinki birth cohort study. Paediatr Perinat Epidemiol. 2015;29(6):515-519.

82. Ueda P, Cnattingius S, Stephansson O, Ingelsson E, Ludvigsson JF, Bonamy AK. Cerebrovascular and ischemic heart disease in young adults born preterm: a population-based Swedish cohort study. Eur $J$ Epidemiol. 2014;29(4):253-260.

83. Tikanmaki M, Tammelin T, Sipola-Leppanen M, et al. Physical fitness in young adults born preterm. Pediatrics. 2016;137(1). Epub 2015 Dec 29.

84. Bassareo PP, Fanos V, Puddu M, Marras S, Mercuro G. Epicardial fat thickness, an emerging cardiometabolic risk factor, is increased in young adults born preterm. J Dev Orig Health Dis. 2016;7(4):369-373.

85. Malin GL, Morris RK, Riley RD, Teune MJ, Khan KS. When is birthweight at term ( $>/=37$ weeks' gestation) abnormally low? A systematic review and meta-analysis of the prognostic and predictive ability of current birthweight standards for childhood and adult outcomes. BJOG. 2015;122(5):634-642. 
Diabetes, Metabolic Syndrome and Obesity: Targets and Therapy

Diabetes, Metabolic Syndrome and Obesity: Targets and Therapy is an international, peer-reviewed open-access journal committed to the rapid publication of the latest laboratory and clinical findings in the fields of diabetes, metabolic syndrome and obesity research. Original research, review, case reports, hypothesis formation, expert opinion and commentaries are all considered for publication. The manuscript management system is completely online and includes a very quick and fair peer-review system, which is all easy to use. Visit http://www.dovepress.com/testimonials.php to read real quotes from published authors.

Submit your manuscript here: https://www.dovepress.com/diabetes-metabolic-syndrome-and-obesity-targets-and-therapy-journal 